\title{
Spatial Distribution of Global Landscape Evaporation in the Early Twenty-First Century by Means of a Generalized Complementary Approach
}

\author{
WILFRIED BRUTSAERT ${ }^{\mathrm{a}}$ \\ School of Civil and Environmental Engineering, Cornell University, Ithaca, New York \\ LEI CHENG \\ State Key Laboratory of Water Resources and Hydropower Engineering Science, Wuhan University, and Hubei \\ Provincial Collaborative Innovation Center for Water Resources Security, Wuhan, China \\ LU ZHANG \\ CSIRO Land and Water, Canberra, Australian Capital Territory, Australia
}

(Manuscript received 10 September 2019, in final form 7 December 2019)

\begin{abstract}
A generalized implementation of the complementary principle was applied to estimate global land surface evaporation and its spatial distribution. The single parameter in the method was calibrated as a function of aridity index, mainly on the basis of runoff and precipitation data for 524 catchments in different parts of the world. The spatial distribution of annual evaporation from Earth's land surfaces for 2001-13 was then calculated at a spatial resolution of $0.5^{\circ}$, by means of an available global net radiation dataset (commonly referred to as CERES SYN1deg-Day) and a global forcing dataset (referred to as CRU-NCEP v7) for nearsurface temperature, humidity, wind speed, and air pressure. The results are shown to agree with reliable previous estimates by more elaborate methods. The global average evaporation for 2001-13 was found to be $472.65 \mathrm{~mm} \mathrm{a}^{-1}$ or $36.96 \mathrm{~W} \mathrm{~m}^{-2}$. The present method should allow not only future updates but also retroactive historical analyses with routine data of net radiation, near-surface air temperature, humidity, wind speed, and precipitation; its main advantage is that the environmental aridity is deduced from atmospheric conditions and requires no knowledge of surface characteristics, such as soil moisture, vegetation, and terrain, which are highly variable and often difficult to quantify at larger spatial scales. Because they are strictly measurement based, the results can serve also as a reality check for different aspects of climate and related models.
\end{abstract}

\section{Introduction}

The main variables in any long term catchment scale water budget studies over Earth's land surfaces are the runoff from the upstream basin $R$, the precipitation rate $P$, and the evaporation rate $E$ averaged over the same area (Brutsaert 2005); for sufficiently long periods, any storage changes can usually be neglected, so that these variables can be linked as follows

$$
R=P-E
$$

\footnotetext{
a ORCID: 0000-0003-1653-6953.
}

Corresponding author: Wilfried Brutsaert,whb2@cornell.edu
(Note that in what follows for simplicity's sake, the term evaporation denotes the combined vaporization of water from vegetation and soil, and it has the same meaning as the term evapotranspiration.) In practical applications in water resources and climate studies, where closure of (1) is required, independent estimates of all three variables are often preferred to assure or assess the quality of the closure. While reliable measurements have been recorded over many years in the case of $P$ and $R$, the estimation of land surface evaporation $E$ is still difficult and long term records are lacking, most notably at the global scale. Early on most available methods of estimating long term regional $E$ were based on (1) and are therefore unavoidably dependent on the features - and shortcomings — of the early records of $R$ and $P$. Critical reviews (Brutsaert 1982) have 
revealed that during the past century or so the $E$ values in the well-known atlases of Baumgartner and Reichel (1975) and of Korzoun et al. (1977, 1978), were probably among the more reliable global estimates of land surface evaporation. In both studies the regional $E$ estimates were constrained by (1). However, these studies were conducted several decades ago, and meanwhile better forcing data have become available; also, since then evaporation has been changing (Brutsaert 2006, 2017). Therefore, the time has come now to revisit them with improved methodologies and more recent and independent information.

Although in recent years major progress has been made in the development of methods to estimate $E$ with other measurements beside $R$ and $P$ (Wang and Dickinson 2012), their application continues to involve many challenges. In one promising development, Bouchet's (1963) complementary principle has received growing attention. In the original formulation of this principle it was not very clear how the different variables are to be estimated, so that the basic idea was slow in being fully appreciated. Over the years several different interpretations have evolved, but in most of the current ones actual evaporation from natural land surfaces is estimated on the basis of the classical concept of potential evaporation and of atmospheric evaporative demand (or apparent potential evaporation). Lately, a generalization of the complementary principle has been presented (Brutsaert 2015), by imposing constraints required by additional physical considerations; this has allowed clarification of the basic assumptions and has given it a more fundamental justification. Since then, the resulting method has been tested and validated with success in a number of different climates and terrain settings at the monthly time scale in China (Liu et al. 2016) and at the daily time scale in Australia (Zhang et al. 2017); China (Brutsaert et al. 2017; Liu et al. 2018), including a high mountainous area (Hu et al. 2018); and Japan (Ai et al. 2017).

It is the main objective here to describe the magnitude and the distribution of the global evaporation from Earth's land surfaces, by applying this most recent formulation of the complementary principle. Because this formulation has evolved somewhat over the past few years, for better transparency of its conceptual basis, first it is briefly reviewed; thus, its theoretical base is strengthened by more clearly redefining the pertinent variables and boundary conditions. Subsequently, the one parameter in the formulation is calibrated with recent terrestrial evaporation data obtained mainly through the water budget in (1) at some 524 catchments worldwide under different climatic and moisture status conditions. The magnitude and distribution of the mean annual evaporation are then calculated with the most recent global meteorological records of net radiation, near-surface air temperature, humidity, and wind speed; the annual time scale was selected as it is the natural choice for global climate studies, which avoids the difficulties in developing a unified calibration scheme for the different areas of Earth with nonconcurrent seasons. The results will be shown to be in good agreement with several reliable recent estimates by more elaborate methods.

\section{The complementary principle and its operative formulation}

\section{a. Basic formulation}

It is generally agreed by now that the actual evaporation $E$ from a natural land surface under drying conditions and the evaporation $E_{\mathrm{pa}}$ from a small wet surface area, placed in the same environment and surrounded by the drying surface from which $E$ is taking place, exhibit complementary behavior; $E_{\mathrm{pa}}$ has been called variously the atmospheric evaporative demand or the apparent potential evaporation (Brutsaert 2005, 2015). Bouchet (1963) who originated this idea, postulated that the deviations of both $E$ and $E_{\mathrm{pa}}$ from the potential evaporation $E_{\mathrm{po}}$, that is, $E-E_{\mathrm{po}}$ and $E_{\mathrm{pa}}-E_{\mathrm{po}}$ are exactly equal but of opposite sign, and this led to his well-known linear relationship

$$
E=2 E_{\mathrm{po}}-E_{\mathrm{pa}}
$$

The potential evaporation $E_{\mathrm{po}}$ is defined here, following Thornthwaite (1948), as the value, which both $E$ and $E_{\mathrm{pa}}$ assume under conditions of ample water availability for evaporation at the surface. Equation (2) has been the subject of many studies and attempted improvements. One such improvement was the assumption in Brutsaert and Parlange (1998) that the two deviations are proportional to each other; this resulted in a more general linear relationship

$$
E=\left[(b+1) E_{\mathrm{po}}-E_{\mathrm{pa}}\right] / b,
$$

in which $b$ is a constant of proportionality, and with which (2) is recovered for $b=1$.

In retrospect, the assumptions leading to (2) and (3) are overly restrictive. Indeed, there is really no fundamental reason why $E_{\mathrm{po}}-E$ should be equal to $E_{\mathrm{pa}}-$ $E_{\mathrm{po}}$, as assumed in (2), or even proportional to each other as assumed in (3); in addition, especially (2), but even (3) allow the unreal possibility of negative $E$ values for large values of the evaporative demand $E_{\mathrm{pa}}$ under 
strongly advective conditions. This difficulty was recognized by Parlange and Katul (1992) who maintained (2) but proposed an adjustment to $E_{\mathrm{po}}$. More recently, in Brutsaert (2015) instead of (2) and (3) the relationship between the deviations was allowed to have a more general form,

$$
E-E_{\mathrm{po}}=-f\left(E_{\mathrm{pa}}-E_{\mathrm{po}}\right) .
$$

In (4) $f()$ is some (at this point) unknown function of the quantity inside the parentheses, to be determined from available boundary conditions, one of which is to avoid negative $E$ values.

It also stands to reason that the complementary deviations of $E$ and $E_{\mathrm{pa}}$ need not be from $E_{\mathrm{po}}$ as a predetermined reference or base, especially since $E_{\mathrm{po}}$ is difficult to estimate when only information and measurements are available about the ambient conditions, which are normally nonpotential. Rather, let it be assumed that these complementary deviations can be from a more flexible base, namely, $\alpha_{c} E_{e}$, in which $\alpha_{c}$ is an adjustable parameter, and $E_{e}$ is the equilibrium evaporation; the latter was originally defined by Slatyer and McIlroy (1961) as

$$
E_{e}=\frac{\Delta}{\Delta+\gamma} Q_{\mathrm{ne}},
$$

in which $\Delta \equiv d e^{*} / d T$ is the slope of the saturation vapor pressure curve, $\gamma$ is the psychrometric constant, and $Q_{\mathrm{ne}}=\left(R_{n}-G\right) / L_{e}$ is the available energy supply rate expressed in evaporation units, with $R_{n}$ the net radiation, $G$ the heat flux into the ground, and $L_{e}$ the latent heat of vaporization. The equilibrium evaporation is a more robust variable than available energy flux; for example, for increasing air temperature, an increasing $\Delta /(\Delta+\gamma)$ will tend to offset a likely decreasing $Q_{\text {ne }}$. The nature of the adjustable parameter $\alpha_{c}$ will be determined and become more evident in what follows. However, in light of the complementarity between $E$ and $E_{\mathrm{pa}}$, it is already clear that the magnitude of the assumed base $\alpha_{c} E_{e}$ must always be intermediate, that is

$$
E \leq \alpha_{c} E_{e} \leq E_{\mathrm{pa}},
$$

and that it should approach potential evaporation, that is, $\alpha_{c} E_{e} \rightarrow E_{\mathrm{po}}$ as potential conditions are being approached, that is when

$$
E=E_{\mathrm{po}}=E_{\mathrm{pa}},
$$

with ample water at and near the surface available for evaporation. These considerations also suggest immediately that under potential conditions $\alpha_{c}$ should have a value of around 1.3, in accordance with the typical values of around 1.26 in the calibration by Priestley and Taylor (1972) for $E_{\mathrm{po}}$, roughly within a range of 1.0-1.5 (Chen and Brutsaert 1995).

With this newly defined base $\alpha_{c} E_{e}$ for the complementary deviations, the relationship between $E$ and $E_{\mathrm{pa}}$ can be recast instead of (4), as follows

$$
E-\alpha_{c} E_{e}=-f\left(E_{\mathrm{pa}}-\alpha_{c} E_{e}\right) .
$$

For the sake of generality, (8) can be expressed in dimensionless terms by introducing $y=E / E_{\mathrm{pa}}$ and $x=$ $\alpha_{c} E_{e} / E_{\mathrm{pa}}$, both of which lie always between 0 and 1 , so that it assumes the form

$$
y=x-F(1-x),
$$

in which $F()$ is the function $f()$ in terms of the dimensionless variables. At this point $F()$ is still unknown, but in the absence of more specific information, it can be expressed as a polynomial, and (9) becomes

$$
y=x-\sum_{i=0}^{n} a_{i} x^{i}
$$

where $n$ is the degree of the polynomial, and $a_{i}$ are coefficients.

The coefficients can be determined by imposing the following four boundary conditions on (10), based on physical considerations: $y=1$ and $(d y / d x)=1$ when $x=1$, and $y=0$ and $(d y / d x)=0$ when $x=0$. The first two conditions are both sufficient and necessary, because all three quantities, namely, $E, \alpha_{c} E_{e}$, and $E_{\mathrm{pa}}$, approach mutual equality shown in (7), as potential conditions are approached, with ample surface moisture availability for evaporation. The third and fourth conditions will prevent the prediction of negative evaporation values; however, they require some further considerations. In the case of the third condition, by virtue of (6) one definitely must have $y=0$ when $x=0$, which means that it is a necessary condition. But this can only be also a sufficient condition if the converse is true, that is if $x \rightarrow 0$ whenever $y \rightarrow 0$. Strictly speaking, it would appear that this may not be the case in general, because $\alpha_{c} E_{e}$ need not vanish when $E$ vanishes. Nevertheless, this condition is satisfied whenever both $x$ and $y$ are very small on their own, either because the available energy $Q_{n e}$ is very small, as during the night or in the wintertime, or because the atmospheric demand $E_{\mathrm{pa}}$ is very large, that is, under very windy and/or very dry conditions [see below in (13) with (14)]. This condition can also be satisfied to a good approximation if the adjustable parameter $\alpha_{c}$ can 
be defined in such a way that it, and thus ipso facto $\alpha_{c} E_{e}$ as well, become sufficiently small under dry climatic conditions, when also $E$ is normally small. This issue will be considered again in section $4 \mathrm{c}$. The fourth condition results from (6), indicating that $E$ is normally smaller than $\alpha_{c} E_{e}$. Imposition of the four conditions (Brutsaert 2015) results finally in

$$
y=2 x^{2}-x^{3}
$$

or, with the original variables, in the following nonlinear relationship,

$$
E=\left(\frac{\alpha_{c} E_{e}}{E_{\mathrm{pa}}}\right)^{2}\left(2 E_{\mathrm{pa}}-\alpha_{c} E_{e}\right) .
$$

The estimation of $E$ by means of (12) requires a knowledge of $E_{\mathrm{pa}}$. This is described next.

\section{b. Practical implementation with ambient climate data}

The atmospheric evaporative demand $E_{\mathrm{pa}}$ can be estimated in a number of ways. In principle, as defined here, it can be measured with a small pan (Kahler and Brutsaert 2006; Brutsaert 2013); however, as already shown in the advection-aridity approach of Brutsaert and Stricker (1979) and subsequent extensions, a good approximation can also be obtained using Penman's $(1948,1956)$ equation, with variables recorded under the ambient, that is, nonpotential, conditions. For the present purpose it can be written as follows

$$
E_{\mathrm{pa}}=\frac{\Delta}{\Delta+\gamma} Q_{\mathrm{ne}}+\frac{\gamma}{\Delta+\gamma} f_{e}\left(u_{2}\right)\left(e_{1}^{*}-e_{1}\right)
$$

in which $u_{2}$ is the mean wind speed at a height $z_{2}$ above the surface, $e_{1}$ is the vapor pressure at a height $z_{1}$ above the surface, and the asterisk indicates saturation. As shown earlier (Zhang et al. 2017; Liu et al. 2018), in the context of the complementary approach the performance of (13) with daily average values of the atmospheric variables is insensitive to the choice of the wind function $f_{e}\left(u_{2}\right)$; thus, it was decided that it can simply be given by Penman's (1948) empirical equation, which avoids the need for surface roughness parameters,

$$
f_{e}\left(u_{2}\right)=0.26\left(1+0.54 u_{2}\right),
$$

in which the constants require that $z_{1}$ and $z_{2}$ are $2 \mathrm{~m}$ above the surface, $u_{2}$ is in meters per second $\left(\mathrm{m} \mathrm{s}^{-1}\right)$, $e_{1}$ is in hectopascals $(\mathrm{hPa})$, and the resulting second term on the right in (13) is in millimeters per day $\left(\mathrm{mm} \mathrm{day}^{-1}\right)$.
With this expression (13) for $E_{\mathrm{pa}}$, and with (5) for $E_{e}$, (12) can be implemented as follows

$$
\begin{aligned}
E= & {\left[\frac{\alpha_{c} \Delta Q_{\mathrm{ne}}}{\Delta Q_{\mathrm{ne}}+\gamma f_{e}\left(u_{2}\right)\left(e_{1}^{*}-e_{1}\right)}\right]^{2} } \\
& \times\left[\left(2-\alpha_{c}\right) \frac{\Delta}{\Delta+\gamma} Q_{\mathrm{ne}}+2 \frac{\gamma}{\Delta+\gamma} f_{e}\left(u_{2}\right)\left(e_{1}^{*}-e_{1}\right)\right] .
\end{aligned}
$$

Equation (15) with the wind function from (14) contains only one parameter, namely, $\alpha_{c}$, which will be estimated by calibration in section 4 .

\section{Evaporation forcing data}

The implementation of (15) with (14) requires data of near-surface air temperature, specific or relative humidity, wind speed, air pressure, net radiation, and ground heat flux. For the present purpose, daily values of the first four variables were taken from the CRUNCEP dataset (version 7; New et al. 1999). This dataset is a merged product consisting of observed mean monthly data by the Climate Research Unit (CRU) of the University of East Anglia, and of the high temporal resolution NCEP reanalysis results produced by NOAA; it is available for the period 1901-2014 with a spatial resolution of $0.5^{\circ}$ at the daily time scale. The atmospheric pressure used in this study was taken as the mean annual pressure. The wind speed data of this dataset, which nominally referred to measurements at $10 \mathrm{~m}$, were reduced to $2 \mathrm{~m}$ above the surface by a mean reduction factor of $0.795\left[(=2 / 10)^{1 / 7}\right]$. Following common practice, the ground heat flux $G$ was neglected at the daily time scale. Daily values of the net radiation were taken from the Clouds and the Earth's Radiant Energy System (CERES) SYN1deg-Day dataset, made available by CERES after March of 2000 with spatial resolution of $1.0^{\circ}$ (Wielicki et al. 1996). The net radiation data at the land surface were resampled to the same resolution as the other forcing data (i.e., $0.5^{\circ}$ ) using a local averaging method. The global average of the CERES SYN1deg-Day dataset (including deserts and polar regions) is about $80 \mathrm{~W} \mathrm{~m}^{-2}$. On the other hand, recent global energy budget studies over land point to a value that is closer to $R_{n}=70 \mathrm{~W} \mathrm{~m}^{-2}$ for the period 2000-10 (Wild et al. 2015); accordingly, the net radiation values at all grid points in this dataset were reduced proportionately to this mean value. The latent heat values to convert the net radiation to evaporation units were calculated using $L_{e}=2.501-0.002361 T_{a}\left(\mathrm{MJ} \mathrm{kg}^{-1}\right)$ with surface air temperatures above freezing and a constant value of $L_{s}=2.835 \mathrm{MJ} \mathrm{kg}^{-1}$ with temperatures below 


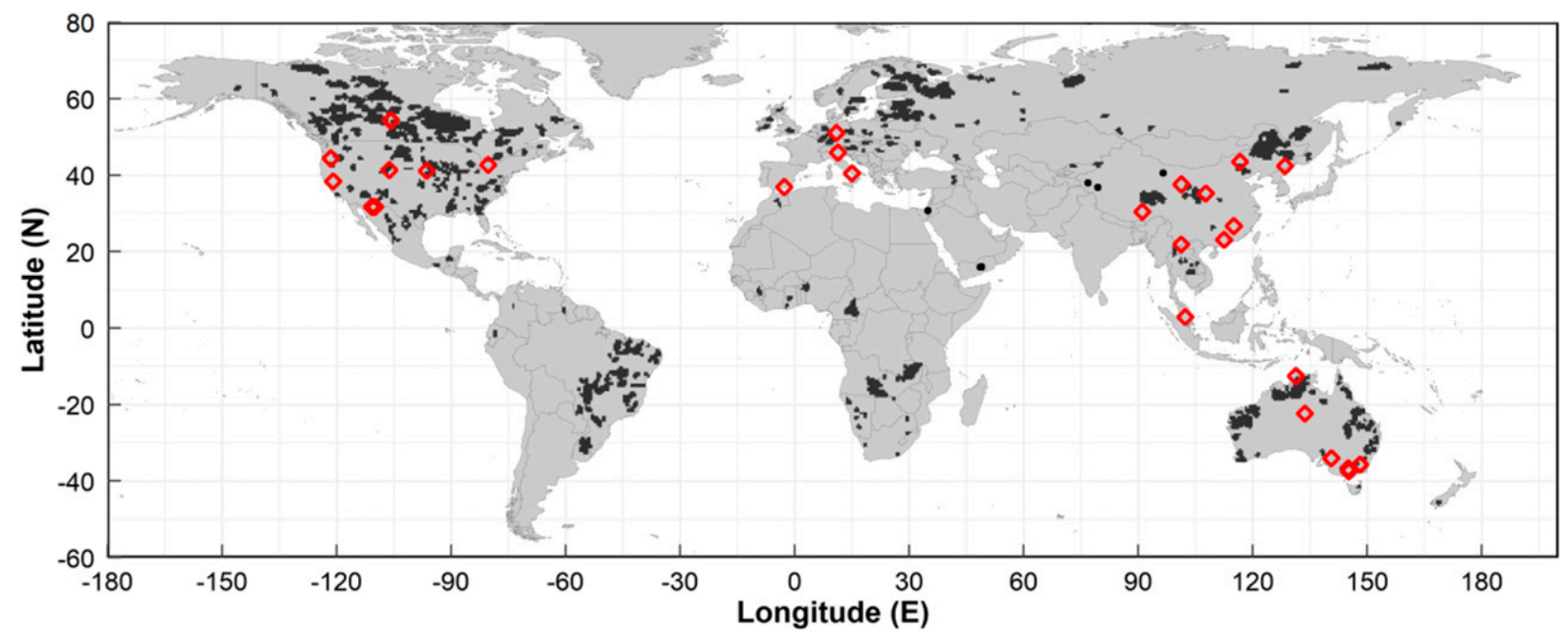

FIG. 1. Spatial coverage of the catchments (areas in black) used in this study $(n=524)$ to establish the relationship between parameter $\alpha_{c}$ and the aridity index; eight catchments among them, whose area shapes could not be recovered are simply shown as black circles. The red open diamonds are locations of the flux stations $(n=32)$ used as extra validation of the established relationship.

freezing for sublimation from snow and ice. The land surface pixels for the present study were identified using a global land and water mask product of the ISLSCP II Project, data collection, with a spatial resolution of $0.5^{\circ}$ (Hall et al. 2006); this was accessed from the Oak Ridge National Laboratory Distributed Active Archive Center (ORNL DAAC; https://daac.ornl.gov). The land evaporation from each grid cell was weighted by the fractional area of each cell using a package "raster" in R (https://cran.r-project.org/web/packages/ raster/).

The forcing data discussed here suffice to calculate $E$ from Earth's land surfaces by means of (15) with (14) over the period 2001-13 at a spatial resolution of $0.5^{\circ}$. However, before (15) can be applied, it is still necessary to estimate the single parameter $\alpha_{c}$. This is described next.

\section{Parameter estimation by global calibration}

When the actual evaporation $E$ is known, the value of parameter $\alpha_{c}$ can be readily solved for by inversion of (15) with (14) using available routine climate forcing data. In this study two different sets of $E$ data were used to calibrate $\alpha_{c}$. One set was derived from the mean annual water balance of selected reference river basins; the other consisted of observed $E$ observations using the eddy covariance technique.

\section{a. With catchment water balance data}

Globally, 524 catchments were identified for which both reliable outflow and precipitation data are available allowing the estimation of evaporation by means of (1). The locations and outlines of these index catchments are depicted in Fig. 1. The 524 catchments have a widespread geographic distribution and have at least 5 years of runoff data available during 2001-13. All of them are largely unregulated and have good consistency between precipitation and runoff. By unregulated is meant that there are no dams or reservoirs within the catchment, according to available datasets on dams at the global and national levels (Lehner et al. 2011). Good consistency between $P$ and $R$ data means that the estimated catchment mean annual $E$ using the water balance method in (1) agrees roughly $( \pm 30 \%)$ with the mean annual evaporation estimated by the Budyko method (Budyko 1974; Zhang et al. 2004). The outflow data from these basins for the period 2001-13 were selected from four different sources, including (i) the Global Runoff Data Centre (http://www.bafg.de/GRDC/EN/Home/homepage_ node); (ii) collation of 780 unregulated Australian catchments produced by Zhang et al. (2013); (iii) the Model Parameter Estimation Experiment (MOPEX) ( $>400)$ across the United States (http://www.nws.noaa.gov/oh/ mopex/index.html); and (iv) runoff data collected by the Chinese Academy of Sciences. Precipitation was taken from the global coverage MSWEP rainfall dataset, with 3-hourly temporal resolution and $0.25^{\circ}$ spatial resolution (Beck et al. 2017; Sun et al. 2018). This MSWEP dataset (version 2.1) was constructed for the period 1979-2017 by merging the highest quality data sources available as function of time scale and location, and as a combination of rain gauge measurements, satellite observations, and estimates from atmospheric models. For each catchment the mean annual precipitation during the period 2001-13 was derived using an area weighted 
averaging method over the grids within the catchment boundary.

With the annual evaporation values thus obtained using (1) for the left hand side of (15), and with the corresponding daily climate forcing data for that same period to calculate daily $\alpha_{c} E_{e}$ and $E_{\mathrm{pa}}$ from which annual averages in the right hand side, (15) was inverted to obtain the mean annual value of the unknown parameter $\alpha_{c}$ for each catchment. The 524 individual values are shown in Fig. 2.

\section{b. With global turbulent flux observations}

Evaporation values from a total of 32 flux stations were used to cross validate the $\alpha_{c}$ values estimated by means of (1) in the previous section. Among them, 21 stations were selected from the global FLUXNET2015 dataset (http://fluxnet.fluxdata.org/), with a minimum availability of $90 \%$ good quality daily data within a year for all the required variables to solve for $\alpha_{c}$ and to calculate the aridity index. The flux data from all stations had been adjusted to ensure energy budget closure, following the suggestion by Twine et al. (2000) and others. The $\alpha_{c}$ values of these 21 stations were also solved at the mean annual time scale with an average of only 2 years of data for each station. The estimated $\alpha_{c}$ values at the 11 remaining stations were collected from previous studies by Zhang et al. (2017), Brutsaert et al. (2017), and Liu et al. (2018). The $\alpha_{c}$ values obtained at the flux stations are shown as red diamonds in Fig. 2.

\section{c. Prediction of the parameter $\alpha_{c}$}

To map the values of $\alpha_{c}$ globally, the following explanatory variables were collected, including the aridity index, that is, $\mathrm{AI}=E_{\mathrm{pa}} / P$, the mean annual temperature $T_{a}$, the mean wind speed, the snowfall fraction, a seasonality index of $T_{a}$, forest coverage fraction, NDVI, and soil water holding capacity. As already found by Liu et al. (2016), a stepwise regression exercise confirmed also here that the aridity index is by far the dominant variable explaining the spatial variability of $\alpha_{c}$; for instance, the additional improvement in $R^{2}$ was only 0.04 for $T_{a}, 0.03$ for mean wind speed, and 0.02 for snowfall fraction, and even less for other variables.

While the aridity index based on total precipitation $P$ was found to be the best explanatory variable in most regions of the world, initial test calculations showed that in cold regions with snow and ice covered surfaces, the use of $P$, consisting of both snow and rain, in AI can lead to unrealistic results for $E$. In hindsight this should not be surprising. Indeed, the purpose of an aridity index is to provide a measure of the availability or lack of water to participate actively in the hydrologic cycle. As long as water is in the solid state as a frozen mass, it is mostly

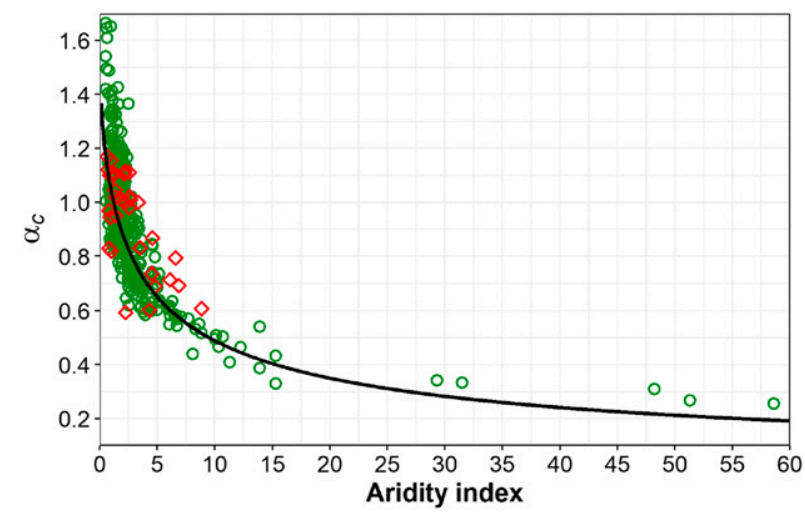

FIG. 2. Estimated values of $\alpha_{c}$ based on inversion of (15) with water balance $E$ data, shown as green open circles $(n=524)$. The estimated values using flux observations are shown as red diamonds $(n=32)$. The optimal relationship (18) as a function of the aridity index, based on rainfall, is represented as a solid line.

immobile and it also exerts a markedly smaller vapor pressure than in its liquid state. As a result, a snow or ice covered landscape is largely barren hydrologically, regardless of the abundance of accumulated solid precipitation or of the thickness of the snow or ice layer on the surface. Thus, the amount of snowfall is not an effective measure of the coexisting wetness or dryness of the landscape. It was decided, therefore, to restrict the definition of AI to "wet" conditions by excluding snowfall, so that $P$ refers to rainfall only; accordingly, for the present purpose the aridity index was redefined as

$$
\mathrm{AI}=E_{\mathrm{pa}} / P_{\text {rain }},
$$

in which $E_{\mathrm{pa}}$ and $P_{\text {rain }}$ were taken as annual mean values.

As shown by Ohmura et al. (1999, Fig. 1) on the basis of measurements in Arctic Canada and Greenland, the fraction of solid precipitation in the monthly total precipitation can be parameterized by the monthly mean air temperature. For the present study, from their data collection the following function was derived for the monthly rainfall

$$
P_{\text {rain }}=P\left(1+a\left\{\tanh \left[b\left(T_{a}-c\right)\right]-d\right\}\right),
$$

where $P$ is the total monthly precipitation both solid and liquid in millimeters of water, $T_{a}$ is the mean monthly air temperature $\left({ }^{\circ} \mathrm{C}\right)$, and the values of the constant parameters were found to be $a=0.496, b=0.215, c=$ 0.622 , and $d=0.958$. In its application, (17) was further constrained by imposing $P_{\text {rain }}=0$ for $T_{a}<-8^{\circ} \mathrm{C}$ and $P_{\text {rain }}=P$ for $T_{a}>+6^{\circ} \mathrm{C}$. The form of (17) was inspired by the work of Dai (2008) to separate $P$ into snowfall and rainfall, but with 3-hourly data. The annual value of $P_{\text {rain }}$ for (16) was obtained by summing the monthly values from (17). 
After testing several functional forms, the following general function was adopted

$$
\alpha_{c}=\frac{a}{\left[1+(b \mathrm{AI})^{c}\right]} .
$$

Optimal values of the three parameters $a, b$, and $c$ were estimated by a genetic algorithm with the objective function considering both the Nash-Sutcliffe efficiency coefficient and bias between the observed values of $E$ [i.e., with (1)] and those estimated using (15) with (18). The optimal values in (18) obtained this way are $a=1.496, b=0.2948$, and $c=0.6697$. The Nash-Sutcliffe efficiency coefficient is $\mathrm{NSE}=0.828$ and the bias is $-4.6 \%$, indicating a good fit. Equation (18) is displayed in Fig. 2 where it can be compared with the $\alpha_{c}$ data. The form of (18) was selected for its flexibility, and it has been used in other contexts as well. For instance, the same form had already been used earlier to describe soil water characteristic functions (Brutsaert 1966, 2005, p. 267); also, forms with supposedly more flexibility through additional parameters, such as proposed by Van Genuchten (1980), did not result in a better goodness of fit.

It is noteworthy that (18) satisfies the constraints on $\alpha_{c}$ inferred earlier behind (5) and in the discussion of the boundary conditions before (11). Thus it yields values of $\alpha_{c}$ around 1.3 for small AI, under very humid conditions, close to Priestley and Taylor's (1972) calibrated value of $\alpha_{c}=1.26$. On the other hand, $\alpha_{c}$ approaches zero under very arid conditions when AI becomes large, as it should, to satisfy the third boundary condition on (10). Figure 3 shows a comparison between the $E$ values calculated using (15) with (18) and the observed values obtained using (1) of the 524 index catchments.

Figure 4 shows how well the catchment evaporation data conform with the theoretical relationship in (11) or (12) and the underlying boundary conditions; thus, $y$ is plotted against $x$ for each of the 524 index catchments according to (11) or (12), in which the $E$ values of the data points are the observed values using (1), and $E_{\mathrm{pa}}$ and $\alpha_{c} E_{e}$ were calculated using (13) and (19) with (18), respectively. The curve in Fig. 4 represents (11), and illustrates the boundary conditions at the lower and upper end.

In a similar way, Fig. 5 validates the complementarity embodied in (9) and (11) or (12) for the 524 index catchments used for the calibration. Thus it illustrates the relationship between the deviations of both $E$ and $E_{\mathrm{pa}}$ from the reference evaporation $\alpha_{c} E_{e}$, that is, $\alpha_{c} E_{e}-E$ and $E_{\mathrm{pa}}-\alpha_{c} E_{e}$.

\section{Global results}

Equation (18) with the available forcing data to estimate $E_{\mathrm{pa}}$ and $P_{\text {rain }}$ for AI in (16) with (17), allowed first the calculation of the global distribution of the

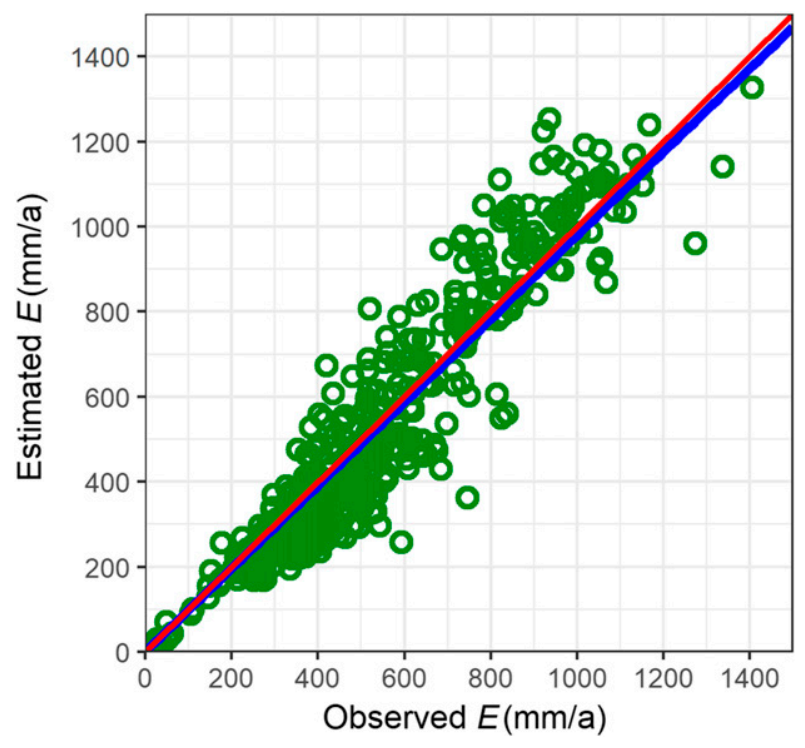

FIG. 3. Comparison between the estimated $E$ values using (15) with (18) and the "observed" values obtained using the water balance (1) of the 524 index catchments shown in Fig. 1 (NSE = $0.828, r=0.94$, bias $=-4.6 \%)$.

parameter $\alpha_{c}$ for each of the $0.5^{\circ} \times 0.5^{\circ}$ pixels covering Earth's land surfaces, except for Antarctica; the results are shown in Fig. 6. No values were calculated over Antarctica, as CRU-NCEP climate forcing data were not available for this continent.

Equation (15) was then used with these values of $\alpha_{c}$ obtained with (18) (and shown in Fig. 6) to predict the mean annual $E$ globally with the same spatial resolution of $0.5^{\circ}$ over the period 2001-13. The resulting distribution of mean evaporation over that entire period is shown in Fig. 7. The global mean surface evaporation from Earth's land areas without Antarctica was calculated to be $519.2 \mathrm{~mm} \mathrm{a}^{-1}$ by area-weighted aggregating of the values for each of the active $0.5^{\circ} \times 0.5^{\circ}$ subareas shown in Fig. 7. Antarctica occupies a total area of roughly $14 \times 10^{6} \mathrm{~km}^{2}$, or about $9.4 \%$ of the total land surface of Earth. As indicated by Van den Broeke et al. (2006) the average evaporation from Antarctica over the period 1980-2004 amounted to about $24 \mathrm{~mm} \mathrm{a}^{-1}$ with no significant trend. Thus, after combining this with the present result the global mean evaporation from the entire land surface of Earth is $E=472.65 \mathrm{~mm} \mathrm{a}^{-1}$ or $36.96 \mathrm{~W} \mathrm{~m}^{-2}$.

\section{Discussion}

The main result derived here, namely, the global average evaporation rate $E=472.65 \mathrm{~mm} \mathrm{a}^{-1}$, is in good agreement with recent estimates by various other methods. Notable among these is the multiyear averaged value 


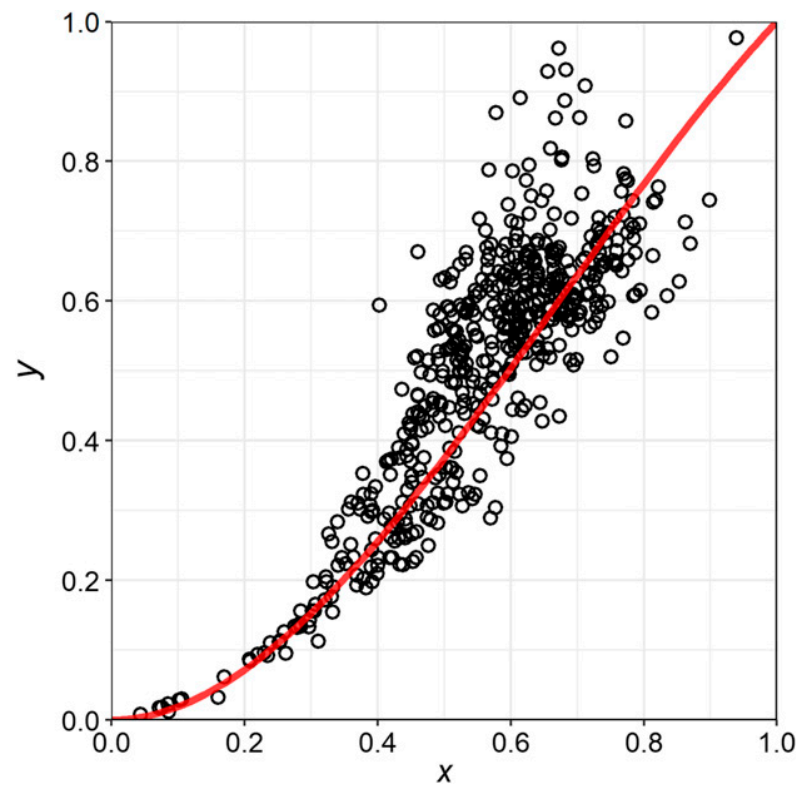

FIG. 4. Scaled evaporation $y=\left(E / E_{\mathrm{pa}}\right)$ as a function of scaled reference evaporation $x=\alpha_{c} E_{e} / E_{\mathrm{pa}}$. The open circles represent all the index catchments $(n=524)$ used to calibrate $\alpha_{c}$ in this study. Thus for the data points the values of $E$ were estimated using catchment water balance data with (1), and $E_{\mathrm{pa}}$ and $\alpha_{c} E_{e}$ were calculated using (13) and (5) with (18), respectively. The smooth curve represents the theoretical complementary function (11).

obtained from global water budget considerations in the review by Wang and Dickinson (2012), namely, $E=474.5 \pm 37 \mathrm{~mm} \mathrm{a}^{-1}$, which is nearly the same as the present result. Very similar are also the mean $E$ values of $38.5 \mathrm{~W} \mathrm{~m}^{-2}$ or $492.4 \mathrm{~mm} \mathrm{a}^{-1}$ in Trenberth et al. (2009, Table 2b), $38 \mathrm{~W} \mathrm{~m}^{-2}$ or $486 \mathrm{~mm} \mathrm{a}^{-1}$ in Wild et al. (2015), and $481.8 \mathrm{~mm} \mathrm{a}^{-1}$ in Rodell et al. (2015, Table 3); these values differ from the present result by only $4.0 \%, 2.7 \%$, and $1.9 \%$, respectively. The present result on mean global evaporation is also remarkably close to the earlier values of $480 \mathrm{~mm} \mathrm{a}^{-1}$ obtained by Baumgartner and Reichel (1975) and $485 \mathrm{~mm} \mathrm{a}^{-1}$ by Korzun et al. (1978) using quite different methods; their atlases with global maps of $P, E$, and $R$ were for many years considered the gold standard in this matter (Brutsaert 1982).

Beside the global averages, it is also of interest to consider the mean latitudinal variation of $E$. The values calculated in the present study are shown in Fig. 8 as $E_{\mathrm{GCRE}}$, where they can be compared with a few mean latitudinal pattern estimates from the literature using widely different methods. For the sake of spatial consistency between the different datasets, the comparison was limited to vegetated surfaces, by considering only the cells with mean annual NDVI $>0.10$, thus excluding deserts and ice covered areas. The following $E$ patterns

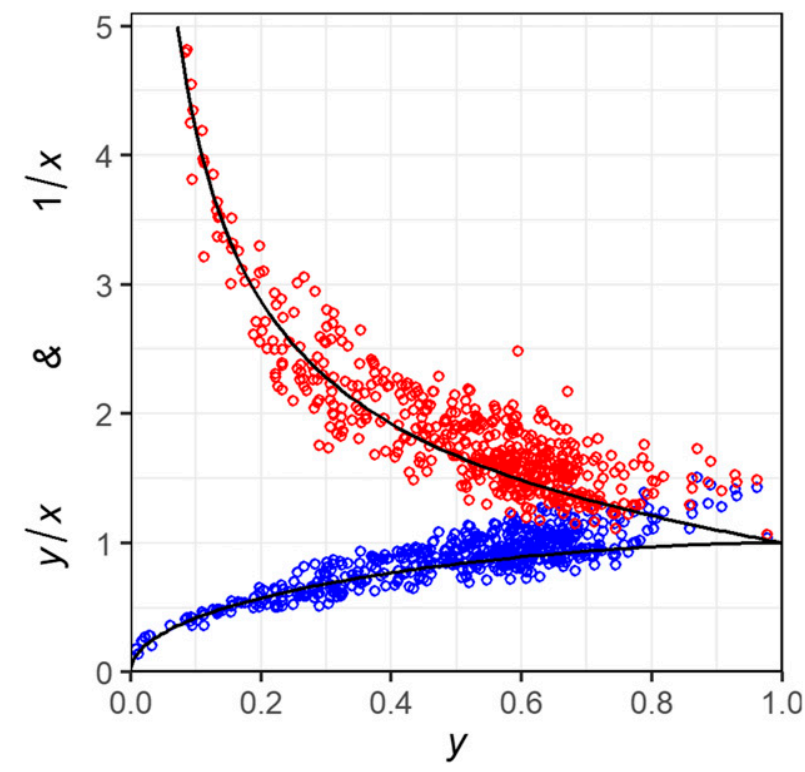

FIG. 5. Illustration of the complementarity between scaled actual evaporation $\left(E / \alpha_{c} E_{e}\right)=y / x$ (blue open circles) and scaled evaporative demand $\left(E_{\mathrm{pa}} / \alpha_{c} E_{e}\right)=1 / x$ (red open circles), at the 524 index catchments; both are displayed in function of $\left(E / E_{\mathrm{pa}}\right)=y$ as a moisture index. The values of $E$ were obtained from measurements with the water budget technique (1), and the values of $E_{\mathrm{pa}}$ and $\alpha_{c} E_{e}$ were calculated using (13) and (5) with (18), respectively. The two curves represent the theoretical complementary function (11).

denoted by their symbols were used for this purpose: $E_{\text {GLEAMv3a }}$ (Miralles et al. 2011), $E_{\mathrm{PML}}$ (Zhang et al. 2016), $E_{\text {MTE }}$ (Jung et al. 2011), $E_{\text {MTE-wB (Zeng et al. }}$ 2014), $E_{\text {ERA }}$ (Dee et al. 2011), and $E_{\text {MERrAs }}$ (Reichle et al. 2011). Admittedly, it is not easy to distinguish the individual curves in Fig. 8 from one another; nevertheless, the main point here is that Fig. 8 shows that the present results, shown in Fig. 7, are fully consistent with the ensemble of latitudinal distributions obtained in other studies with mostly more elaborate methodologies.

In addition to mean values, the reliability of the present results can also be gauged by considering certain more restricted areas with known values of $E$, from detailed studies by others. A few cases of special interest come to mind. At the lower and colder extreme, the average evaporation from Greenland was estimated to be on the order of $35 \mathrm{~mm} \mathrm{a}^{-1}$ (Ohmura et al. 1999) and similarly 28 or $55 \mathrm{~mm} \mathrm{a}^{-1}$, depending on the method (Box and Steffen 2001). At the "Third Pole", the average evaporation from the Tibetan Plateau has been estimated to be around $250 \mathrm{~mm} \mathrm{a}^{-1}$ (Zhang et al. 2007). In a more temperate region, the average evaporation from the Mississippi basin was estimated to be $637 \mathrm{~mm} \mathrm{a}^{-1}$ (Milly and Dunne 2001). At the high extreme, the evaporation from the Amazonian forest 


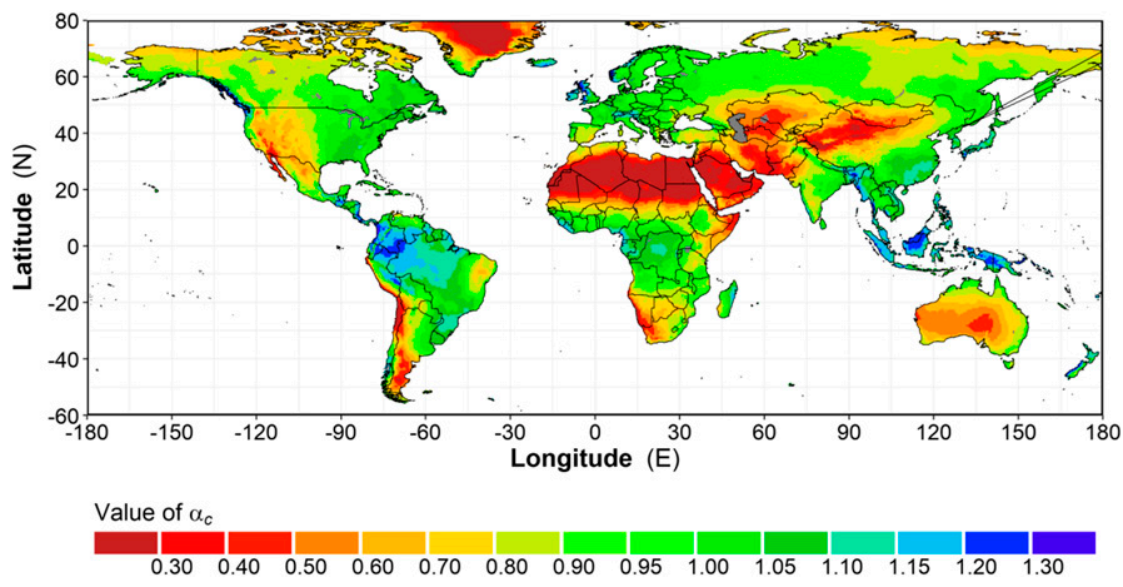

FIG. 6. Global distribution of the parameter $\alpha_{c}$, as calculated by means of (18).

was estimated and reviewed to be on the order of $1311 \mathrm{~mm} \mathrm{a}^{-1}$ (Xu et al. 2019). Inspection of Fig. 7 shows that the mean $E$ values for these specific regions generally support the values displayed in color in the map.

\section{Conclusions}

The generalized form of the complementary principle, as implemented herein, was found to be a realistic descriptor of regional landscape evaporation by means of standard meteorological data. The method had yielded excellent results in several recent studies dealing with evaporation over smaller regions with widely different terrain and climates. However, the present study is the first instance of its successful use in a predictive mode at the global scale. Already in the calibration phase good agreement was observed between the estimates with the proposed complementary method and the evaporation data obtained from the 524 catchments of different sizes and the 32 flux stations in different parts of the world (Fig. 1). Finally, the main result, namely, the global evaporation calculated herein, was found to be in good agreement with several of the more reliable estimates of global evaporation in recent studies using totally different methods with more stringent data requirements.

One of the main advantages of the present approach is that no knowledge is required of surface characteristics, such as soil moisture, vegetation, and topography that tend to be highly variable and often unreliable. Thus only standard meteorological data are needed; these comprise net radiation, near surface air temperature, near surface air humidity, wind speed, and long-term mean precipitation. With these types of routine data, the method is simple and robust enough to permit not only future updates of the present results but also retroactive historical analyses. Moreover, because the obtainable results are based strictly on such measurements, they

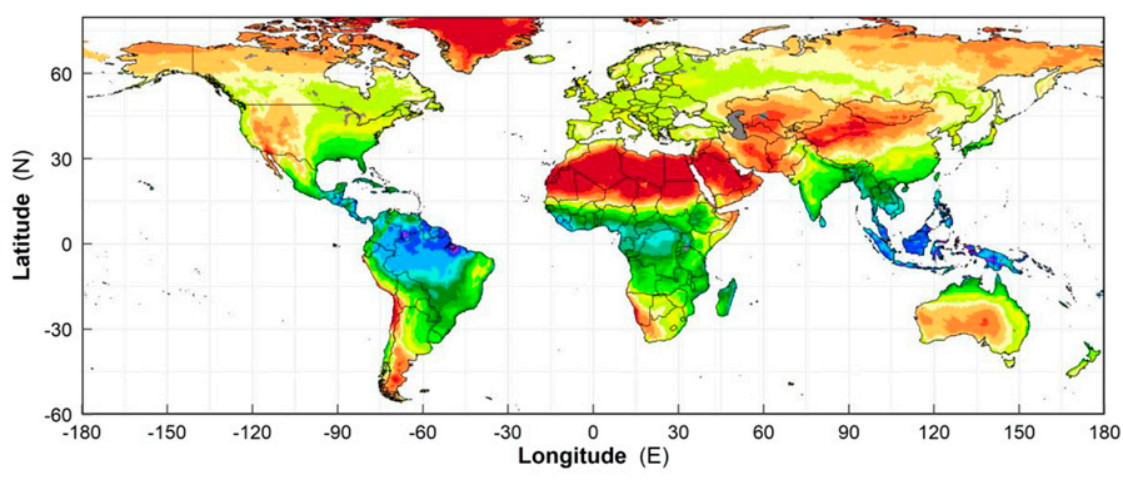

Mean annual evaporation $\left(\mathrm{mm} \mathrm{a}^{-1}\right)$

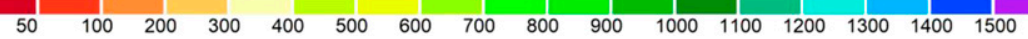

FIG. 7. Global distribution of the mean annual evaporation $\left(\mathrm{mm} \mathrm{a}^{-1}\right)$ over the period $2000-13$, as calculated by means of the generalized complementary relationship (15) with (18). 


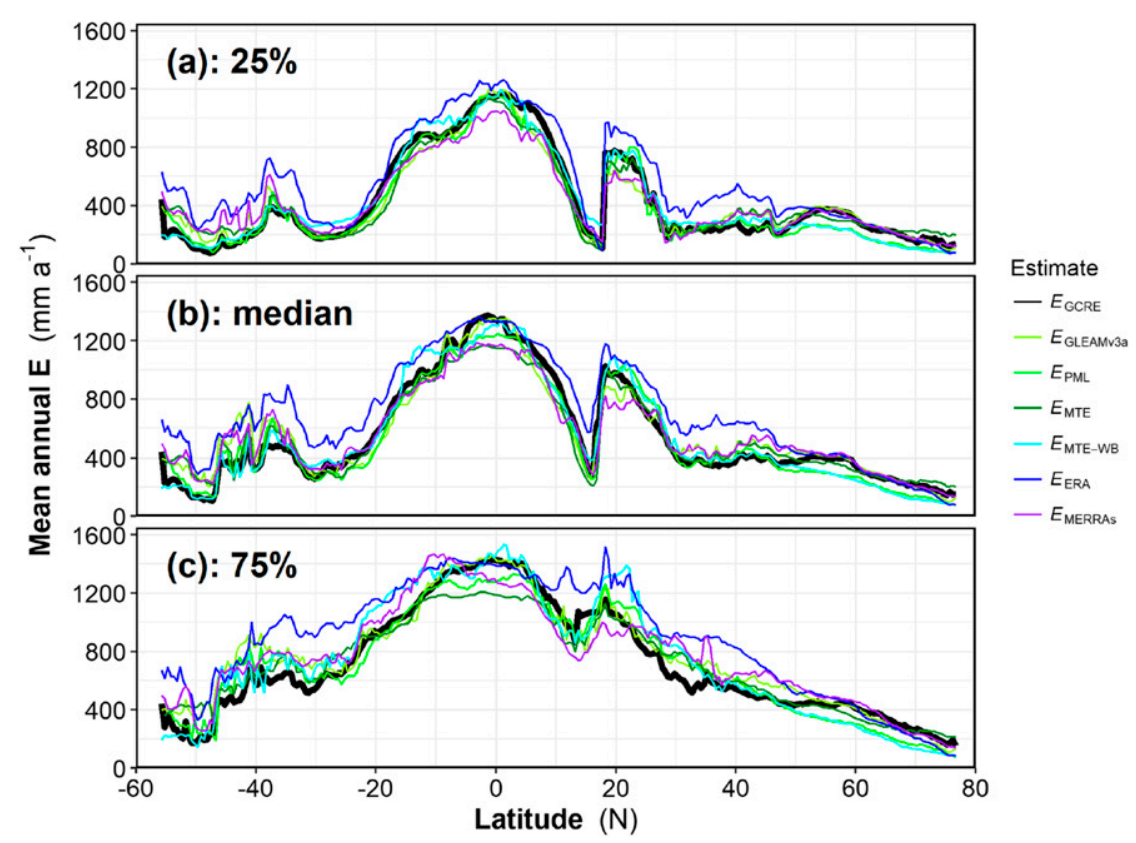

FIG. 8. Comparison of latitudinal patterns of estimated global $E$ (vegetated cells only, which were masked with mean annual NDVI $>0.1$ ) shown in Fig. 7 with those of other independent estimates $(n=7)$. Shown are three different quantiles, (a) $25 \%$, (b) median, and (c) $75 \%$ of mean annual $E$ of all the land cells over the same latitudinal band. The solid black lines $\left(E_{\mathrm{GCRE}}\right)$ represent the estimate using the present method, namely, (15) with (18), and shown in Fig. 7. The lines in different colors represent seven independent estimates as described in the text.

can be useful for independent reality checks for different aspects of climate and related model calculations. Analysis of global evaporation trends in recent years with the present method is ongoing and will be the subject of a future communication.

Acknowledgments. The authors wish to thank Xiaomang Liu, who provided information to validate some aspects of Fig. 2, and Yongqiang Zhang, who provided part of the global catchment data; both are currently at the Chinese Academy of Sciences, Beijing. The authors are also grateful for the support by the National Natural Science Foundation of China (41890822; 51879193; 51861125102) and the National Key Research and Development Program of China (2018YFC0407202).

\section{REFERENCES}

Ai, Z., Q. Wang, Y. Yang, K. Manevski, X. Zhao, and D. Eer, 2017: Estimation of land-surface evaporation at four forest sites across Japan with the new nonlinear complementary method. Sci. Rep., 7, 17793, https://doi.org/10.1038/ s41598-017-17473-0.

Baumgartner, A., and E. Reichel, 1975: The World Water Balance: Mean Annual Global, Continental and Maritime Precipitation, Evaporation and Run-Off. Elsevier Scientific Publishing Company, 179 pp.
Beck, H. E., A. I. J. M. van Dijk, V. Levizzani, J. Schellekens, D. G. Miralles, B. Martens, and A. de Roo, 2017: MSWEP: 3-hourly $0.25^{\circ}$ global gridded precipitation (1979-2015) by merging gauge, satellite, and reanalysis data. Hydrol. Earth Syst. Sci., 21, 589-615, https://doi.org/10.5194/hess-21-589-2017.

Bouchet, R. J., 1963: Evapotranspiration réelle, evapotranspiration potentielle, et production agricole. Ann. Agron., 14, 743-824.

Box, J. E., and K. Steffen, 2001: Sublimation on the Greenland ice sheet from automated weather station observations. J. Geophys. Res., 106, 33 965-33 981, https://doi.org/10.1029/2001JD900219.

Brutsaert, W., 1966: Probability laws for pore-size distributions. Soil Sci., 101, 85-92, https://doi.org/10.1097/00010694-196602000-00002.

_ 1982: Evaporation into the Atmosphere: Theory, History and Applications. Springer, 299 pp.

—, 2005: Hydrology: An Introduction. Cambridge University Press, $605 \mathrm{pp}$.

- 2006: Indications of increasing land surface evaporation during the second half of the 20th century. Geophys. Res. Lett., 33, L20403, https://doi.org/10.1029/2006GL027532.

_ 2013: Use of pan evaporation to estimate terrestrial evaporation trends: The case of the Tibetan Plateau. Water Resour. Res., 49, 3054-3058, https://doi.org/10.1002/wrcr.20247.

— 2015: A generalized complementary principle with physical constraints for land-surface evaporation. Water Resour. Res., 51, 8087-8093, https://doi.org/10.1002/2015WR017720.

__, 2017: Global land surface evaporation trend during the past half century: Corroboration by Clausius-Clapeyron scaling. Adv. Water Resour., 106, 3-5, https://doi.org/10.1016/ j.advwatres.2016.08.014. 
, and H. Stricker, 1979: An advection-aridity approach to estimate actual regional evapotranspiration. Water Resour. Res., 15, 443-450, https://doi.org/10.1029/WR015i002p00443.

— , and M. B. Parlange, 1998: Hydrologic cycle explains the evaporation paradox. Nature, 396, 30, https://doi.org/10.1038/23845.

—- W. Li, A. Takahashi, T. Hiyama, L. Zhang, and W. Liu, 2017: Nonlinear advection-aridity method for landscape evaporation and its application during the growing season in the southern Loess Plateau of the Yellow River basin. Water Resour. Res., 53, 270-282, https://doi.org/10.1002/ 2016WR019472.

Budyko, M. I., 1974: Climate and Life. Academic Press, 508 pp.

Chen, D., and W. Brutsaert, 1995: Diagnostics of land surface spatial variability and water vapor flux. J. Geophys. Res., 100, 25 595-25 606, https://doi.org/10.1029/95JD00973.

Dai, A., 2008: Temperature and pressure dependence of the rainsnow phase transition over land and ocean. Geophys. Res. Lett., 35, L12802, https://doi.org/10.1029/2008GL033295.

Dee, D. P., and Coauthors, 2011: The ERA-Interim reanalysis: Configuration and performance of the data assimilation system. Quart. J. Roy. Meteor. Soc., 137, 553-597, https://doi.org/ 10.1002/qj.828.

Hall, F. G., and Coauthors, 2006: The ISLSCP Initiative II Global Data sets: Surface boundary conditions and atmospheric forcings for land-atmosphere studies. J. Geophys. Res., 111, D22S01, https://doi.org/10.1029/2006JD007366.

Hu, Z., G. Wang, X. Sun, M. Zhu, C. Song, K. Huang, and X. Chen, 2018: Spatial-temporal patterns of evapotranspiration along an elevation gradient on Mount Gongga, Southwest China. Water Resour. Res., 54, 4180-4192, https://doi.org/10.1029/ 2018WR022645.

Jung, M., and Coauthors, 2011: Global patterns of land-atmosphere fluxes of carbon dioxide, latent heat, and sensible heat derived from eddy covariance, satellite, and meteorological observations. J. Geophys. Res., 116, G00J07, https://doi.org/10.1029/ 2010JG001566.

Kahler, D. M., and W. Brutsaert, 2006: Complementary relationship between daily evaporation in the environment and pan evaporation. Water Resour. Res., 42, W05413, https://doi.org/ 10.1029/2005WR004541.

Korzoun, V. I., and Coauthors, Eds., 1977: Atlas of the World Water Balance. USSR National Committee for the International Hydrological Decade, UNESCO Press, 65 map plates, 36 pp.

Korzun, V. I., and Coauthors, 1978: World Water Balance and Water Resources of the Earth. USSR National Committee for the International Hydrological Decade, UNESCO Press, 663 pp.

Lehner, B., and Coauthors, 2011: High-resolution mapping of the world's reservoirs and dams for sustainable river-flow management. Front. Ecol. Environ., 9, 494-502, https://doi.org/ $10.1890 / 100125$.

Liu, X., C. Liu, and W. Brutsaert, 2016: Regional evaporation estimates in the eastern monsoon region of China: Assessment of a nonlinear formulation of the complementary principle. Water Resour. Res., 52, 9511-9521, https://doi.org/10.1002/ 2016WR019340.

,-- , and,- 2018 : Investigation of a generalized nonlinear form of the complementary principle for evaporation estimation. J. Geophys. Res. Atmos., 123, 3933-3942, https:// doi.org/10.1002/2017JD028035.

Milly, P. C. D., and K. A. Dunne, 2001: Trends in evaporation and surface cooling in the Mississippi River basin. Geophys. Res. Lett., 28, 1219-1222, https://doi.org/10.1029/2000GL012321.
Miralles, D. G., R. A. M. De Jeu, J. H. Gash, T. R. H. Holmes, and A. J. Dolman, 2011: Magnitude and variability of land evaporation and its components at the global scale. Hydrol. Earth Syst. Sci., 15, 967-981, https://doi.org/10.5194/hess-15-9672011.

New, M., M. Hulme, and P. Jones, 1999: Representing twentiethcentury space-time climate variability. Part I: Development of a 1961-90 mean monthly terrestrial climatology. J. Climate, 12, 829-856, https://doi.org/10.1175/1520-0442(1999)012<0829: RTCSTC $>2.0 . C O ; 2$.

Ohmura, A., P. Calanca, M. Wild, and M. Anklin, 1999: Precipitation, accumulation and mass balance of the Greenland ice sheet. $Z$. Gletscherk. Glazialgeol., 35, 1-20.

Parlange, M. B., and G. Katul, 1992: An advection-aridity evaporation model. Water Resour. Res., 28, 127-132, https://doi.org/ 10.1029/91WR02482.

Penman, H. L., 1948: Natural evaporation from open water, bare soil, and grass. Proc. Roy. Soc. Ser. A, 193, 120-145, https:// doi.org/10.1098/rspa.1948.0037.

, 1956: Evaporation: An introductory survey. Neth. J. Agric. Sci., 4, 9-29.

Priestley, C. H. B., and R. J. Taylor, 1972: On the assessment of surface heat flux and evaporation using large-scale parameters. Mon. Wea. Rev., 100, 81-92, https://doi.org/10.1175/ 1520-0493(1972) $100<0081$ :OTAOSH $>2.3 . \mathrm{CO} ; 2$.

Reichle, R. H., R. D. Koster, G. J. M. De Lannoy, B. A. Forman, Q. Liu, S. P. P. Mahanama, and A. Touré, 2011: Assessment and enhancement of MERRA land surface hydrology estimates. J. Climate, 24, 6322-6338, https://doi.org/10.1175/ JCLI-D-10-05033.1.

Rodell, M., and Coauthors, 2015: The observed state of the water cycle in the early twenty-first century. J. Climate, 28, 82898318, https://doi.org/10.1175/JCLI-D-14-00555.1.

Slatyer, R. O., and I. C. McIlroy, 1961: Practical Microclimatology. CSIRO, $310 \mathrm{pp}$.

Sun, Q., C. Miao, Q. Duan, H. Ashouri, S. Sorooshian, and K.-L. Hsu, 2018: A review of global precipitation data sets: Data sources, estimation, and intercomparisons. Rev. Geophys., 56, 79-107, https://doi.org/10.1002/2017RG000574.

Thornthwaite, C. W., 1948: An approach toward a rational classification of climate. Geogr. Rev., 38, 55-94, https://doi.org/ 10.2307/210739.

Trenberth, K. E., J. T. Fasullo, and J. Kiehl, 2009: Earth's global energy budget. Bull. Amer. Meteor. Soc., 90, 311-323, https:// doi.org/10.1175/2008BAMS2634.1.

Twine, T. E., and Coauthors, 2000: Correcting eddy-covariance flux underestimates over a grassland. Agric. For. Meteor., 103, 279300, https://doi.org/10.1016/S0168-1923(00)00123-4.

Van den Broeke, M., W. J. Van den Berg, E. Van Meijgaard, and C. Reijmer, 2006: Identification of Antarctic ablation using a regional atmospheric model. J. Geophys. Res., 111, D18110, https://doi.org/10.1029/2006JD007127.

Van Genuchten, M. T., 1980: A closed form equation for predicting the hydraulic conductivity of unsaturated soils. Soil. Sci. Soc. Amer. J., 44, 892-898, https://doi.org/10.2136/ sssaj1980.03615995004400050002x.

Wang, K., and R. E. Dickinson, 2012: A review of global terrestrial evapotranspiration: Observation, modeling, climatology, and climatic variability. Rev. Geophys., 50, RG2005, https://doi.org/10.1029/2011RG000373.

Wielicki, B. A., B. R. Barkstrom, E. F. Harrison, R. B. Lee, G. L. Smith, and J. E. Cooper, 1996: Clouds and the Earth's Radiant Energy System (CERES): An Earth observing system exper- 
iment. Bull. Amer. Meteor. Soc., 77, 853-868, https://doi.org/ 10.1175/1520-0477(1996)077<0853:CATERE>2.0.CO;2.

Wild, M., and Coauthors, 2015: The energy balance over land and oceans: An assessment based on direct observations and CMIP5 climate models. Climate Dyn., 44, 3393-3429, https:// doi.org/10.1007/s00382-014-2430-z.

Xu, D., E. Agee, J. Wang, and V. Y. Ivanov, 2019: Estimation of evapotranspiration of Amazon rainforest using the maximum entropy production method. Geophys. Res. Lett., 46, 14021412, https://doi.org/10.1029/2018GL080907.

Zeng, Z. Z., T. Wang, F. Zhou, P. Ciais, J. F. Mao, X. Y. Shi, and S. L. Piao, 2014: A worldwide analysis of spatiotemporal changes in water balance-based evapotranspiration from 1982 to 2009. J. Geophys. Res. Atmos., 119, 1186-1202, https:// doi.org/10.1002/2013JD020941.

Zhang, L., K. Hickel, W. R. Dawes, F. H. S. Chiew, A. W. Western, and P. R. Briggs, 2004: A rational function approach for estimating mean annual evapotranspiration. Water Resour. Res., 40, W02502, https://doi.org/10.1029/2003WR002710.

- L. Cheng, and W. Brutsaert, 2017: Estimation of land surface evaporation using a generalized nonlinear complementary relationship. J. Geophys. Res. Atmos., 122, 1475-1487, https:// doi.org/10.1002/2016JD025936.

Zhang, Y., C. Liu, Y. Tang, and Y. Yang, 2007: Trends in pan evaporation and reference and actual evapotranspiration across the Tibetan Plateau. J. Geophys. Res., 112, D12110, https://doi.org/ 10.1029/2006JD008161.

_ , and Coauthors, 2013: Collation of Australian modeler's streamflow dataset for 780 unregulated Australian catchments. CSIRO Land and Water, 115 pp., https://doi.org/ $10.4225 / 08 / 58$ b5 baad 4 fcc 2

— trial evapotranspiration and its components. Sci. Rep., 6 , 19124, https://doi.org/10.1038/srep19124. 